\title{
The Effect of Electroless Bath Parameters and Heat Treatment on the Properties of Ni-P and Ni-P-Cu Composite Coatings
}

\author{
Seyyed Hashem Mousavi Anijdan ${ }^{a}$, Masoud Sabzi ${ }^{b *}$, Mostafa Roghani Zadeh ${ }^{b}$, Mansour Farzam $^{c}$ \\ ${ }^{a}$ Young Researchers and Elites Club, Science and Research Branch, Islamic Azad University, \\ Tehran, Iran \\ ${ }^{b}$ Department of Materials Engineering, Ahvaz Branch, Islamic Azad University, Ahvaz, Iran \\ 'Department of Technical Inspection, Petroleum University of Technology, Abadan, Iran
}

Received: October 30, 2017; Accepted: November 19, 2017

\begin{abstract}
Ni-P-(Cu) composite coatings were applied on a St37 steel in an acidic bath of hypophosphite composite. The effect of the concentration of the $\mathrm{Cu}$ particles and $\mathrm{pH}$ of the solutionon the amount of Ni and $\mathrm{P}$ of the coatings, their morphology, and hardness of the coatings were explored. Some of the coated samples were also heat treated at $400^{\circ} \mathrm{C}$ for 1 hour. The phases formed, the microstructure and the amount of the alloying elements of the coatings were analyzed by X-Ray powder diffraction (XRD), Scanning Electron Microscope (SEM) equiped with Energy Dispersive Spectroscopy (EDS). Results show that although adding $\mathrm{Cu}$ particles reduced the hardness of Ni-P coating (from 482.4 to 351.2 VH in $1 \mathrm{gr} /$ lit $\mathrm{Cu}$ ), within Ni-P-Cu composite coatings the hardness of Ni-P-Cu composite coating increased from 351.2 to $380.7 \mathrm{VH}$ by increasing the $\mathrm{Cu}$ particles from 1 to $7 \mathrm{gr} /$ lit. The structure of the coating was crystalline during the heat treatment making the coating harder. With increasing the $\mathrm{pH}$ of the solution from 4.5 to 7 and then to 9 , the weight percent of $\mathrm{P}$ and the particle of $\mathrm{Cu}$ were reduced.
\end{abstract}

Keywords: Cu particle, composite coating, hardness, morphology.

\section{Introduction}

Electroless is a chemical process that is applied naturally on a metal surface. ${ }^{1}$ The thickness of the coating increases linearly so long as the chemical composition of the solution is kept constant. Electroless technology was invented by Brenner and Riddell in $1946 .{ }^{2}$ Generally, metal surfaces and alloys have deficiencies such as low strength, low corrosion resistance, inappropriate wear resistance etc. Some of these deficiencies can be overcome by adding alloying elements as in the case of stainless steels. ${ }^{3}$ By adding a few layers on the surface of a metal through electroless process most of the surface characteristics can be improved to reach in an appropriate level. Ni electroless is used particularly for making a uniform and continuous metal coating. ${ }^{1} \mathrm{Ni}$ electroless coatings are industrially important due to their unique properties such as excellent adhesion to the sub-layer, uniform thickness, high level of hardness and wear resistance etc. Among Ni electroless coatings, Ni-P electroless coating is of important category. This latter coating is widely used in industry due to its high hardness, amorphous structure, and good machining capabilities. Phosphor content of these coatings is critical in defining the structure and subsequently the properties of the coating. Coatings with low amount of $\mathrm{P}$ (between 1 to $4 \mathrm{wt} \%$ ) have crystalline microstructure. Coatings with average amount of $\mathrm{P}$ (between 4 to $7 \mathrm{wt} \%$ ) have a mixed crystalline-amorphous microstructure. And

*e-mail: mas.metallurg88@gmail.com coatings with high level of $\mathrm{P}$ (between 7 to $13 \mathrm{wt} \%$ ) have amorphous microstructure..$^{4-9}$

Depending on the reducing agent of the coating, Ni coatings are divided to Ni-P coating and Ni-B coating. Alkaline Ni-P baths are used for coaitng of polymeric specimen since they can be applied at low temperatures. These coatings have good soldering characteristics and are used in electronic devices. Due to low temperature of the bath in the alkalin environment, they consume lower energy compared with the acidic ones. Moreover, the stability of alkaline baths are higher than the acidic ones. On the other hand, low coating rate is the main drawback of the alkaline coatings. As well, alkaline coatings can not be used for some metals, especially some aluminum alloys. ${ }^{10-14}$

Of the important parameters on the electroplating rate and the properties of Ni-P electroless coatings is the $\mathrm{pH}$ of the solution. Depending on the chemical composition, the electroless acidic baths work in a specific $\mathrm{pH}$ range. In these baths the electroless is stopped once $\mathrm{pH}$ reaches values below 4. During the electroless process, as the reactions progress, which results in the produciton of hydrogen and reduction of $\mathrm{Ni}, \mathrm{H}^{+}$concentration increses in the bath and the $\mathrm{pH}$ of the solution continuously reduces as such. Therefore, the presence of buffer or addition of $\mathrm{OH}^{-}$agent is necessary to control the $\mathrm{pH}$. To control the $\mathrm{pH}, \mathrm{NaOH}$ can be added to the solution as well. ${ }^{12-17}$

Heat treatment is usually performed on the Ni-P electroless coatings to improve the properties such as hardness, 
adhesiveness, resistance to creep, resistance to wear. Structural changes occur in these coatings when heated above 220$260^{\circ} \mathrm{C}$ temperature range. In such a situation, firstly $\mathrm{Ni}_{3} \mathrm{P}$ particles, with the same crystal structure as the coating, form in the matrix and subsequently other independent particles precipitate as well. The precipitates get crystallized above $320^{\circ} \mathrm{C}$ and their amorphous characteristics reduce. As the heating continuous, the $\mathrm{Ni}_{3} \mathrm{P}$ conglomerate and a two phase alloy form. Coatings with more than $8 \mathrm{wt} \% \mathrm{P}$ contain $\mathrm{Ni}_{3} \mathrm{P}$ matrix, whereas for coatings with less than this amount of $\mathrm{P}$, the matrix is pure $\mathrm{Ni}$. The formation of $\mathrm{Ni}_{3} \mathrm{P}$ increases hardness and resistance to wear at the expense of formability and resistance to corrosion. ${ }^{18-21}$

Temperature is another important factor for the properties of Ni-P electroless coatings. It was found that the reductioning agent and the complexing agent in the Ni-P electroless process is dependent on the temperature. In the baths with sodium hypophosphate, temperature has a significant effect on the coating. At temperature below $65^{\circ} \mathrm{C}$, the rate of precipitation in the coating is negligible. As the temperature increases, the precipitation increases substantially as such. To achieve a precipitation rate of 10 micrometer per hour the temperature of the solution should be above $80^{\circ} \mathrm{C}$. As well, to obtain a constant coating, the temperature should be the same in the whole bath. This is often done by the agitation of the solution. In most acidic baths, appropriate temperature range is between $85^{\circ} \mathrm{C}$ and $95^{\circ} \mathrm{C}$. In addition to the rate of coating, the temperature influences on the percentage of $\mathrm{P}$ in a way that increasing the temperature of the electroless bath reduces the $\mathrm{P}$ content of the coating. ${ }^{22-24}$

Guo et ${ }^{25}$ investigated the effect of reverse pulse ratio and frequency on the morphology and hardness as well as on the corrosion resistance of $\mathrm{Ni}-\mathrm{C}$ composite electroless coatings. They found that increasing the reverse pulse ratio and the frequency resulted in a more homogeneous coating. As well, the hardness of the coating was increased with increasing the reverse pulse ratio and reduced with the increase of frequency. The composition of the electroless bath is another parameter affecting the properties of Ni electroless. Anik et al ${ }^{26}$ investigated the effect of the composition of the bath on the properties of Ni-B electroless film and defined some optimum condition of the bath for the electroless purposes.

In terms of the effect of $\mathrm{Cu}$ on Ni-P coatings, it was claimed that adding $\mathrm{Cu}$ enhances brightness, corrosion behavior and thermal stabilty as the expense of fatigue properties in the coatings. ${ }^{27}$ Considering the points mentioned above, there are still important electroless parameters affecting the properties of Ni-P electroless coatings which have not been fully explored to date. As well, the heat treatment condition of these coatings is of critical importance in changing properties such as morphology, hardness, wear resistance, and corrosion resistance etc. The effect of heat treatment on these particular coatings was not explained in the literature. Therefore, this research is focused on elucidating the effect of electroless bath parameters as well as heat treatment condition on the propeties of Ni-P and Ni-P-Cu composite coatings.

\section{Materials and Experimental Procedure}

\subsection{Materials}

St37 steel was used as the sub-layer. Table 1 gives the composition of the St37 steel used for this research. St37 specimens with the dimensions of $2 * 5 \mathrm{~cm}$ were prepared as sub-layer. After cleaing the surface of the specimens with the sand papers, they were rinsed by distilled water. The layer was then put in a $50 \mathrm{wt} \% \mathrm{HCl}$ solution for 60 second after which it was again rinsed by distilled water.

\subsection{Electroplating bath}

Samples were put in Ni electroplating bath under 0.10.2 AMP for 3-5 minutes prior to coating. This process was performed to make nucleation sites of $\mathrm{Ni}$, due to catalitic effect, and make Ni precipitation in the next electroless step for the precipitation of $\mathrm{Ni}$ and $\mathrm{P}$ on the sub-layer more probable [8]. Acidic baths were used for this purpose since acidic baths have better stability and produce coatings with higher quality. Table 2 gives the composition and the conditions of these acidic baths. Nickel sulfide as the source of Ni was used. Sodium hypophosphite was used as the reductioning agent and also as the source of $\mathrm{P}$. In addition, lactic acid was used as the complexing agent to control free $\mathrm{Ni}$ ions. Heavy metals such as $\mathrm{Pb}$ were also used to stabilize the solution and prevent the decomposition of the bath. The sub-layer was put into the electroless bath vertically. A layer of Ni-P was applied in an electroless bath. Then, $\mathrm{Cu}$ was added to this layer to form composite Ni-P-Cu layer. The effect of different parameters such as the concentration of $\mathrm{Cu}$ particles, and $\mathrm{pH}$ of the solution, on the weight percent of $\mathrm{Ni}$ and $\mathrm{P}$ in the coating, morphology of the coating, and hardness of the coating were investigated. As well, the effect of heat treatment on the structure of the coating was analyzed. Heat treatment was conducted in the $\mathrm{pH}$ of 4.5 to 5 , under the rotating speed of $400 \mathrm{rpm}$ at the temperature of $85^{\circ} \mathrm{C}$. The temperature of the baths in the simple Ni-P coating and in the composite coating were constant.

Particles were added to the electroless bath of Ni-P to make composite coating of Ni-P-Cu. The bath was then rotated for one hour with the speed of $1000 \mathrm{rpm}$. This was performed to prevent the precipitation of the particles and

Table 1. Chemical composition of St37 samples used as sub-layer.

\begin{tabular}{lccccccccc}
\hline Element & $\mathrm{Al}$ & $\mathrm{Cr}$ & $\mathrm{Ni}$ & $\mathrm{S}$ & $\mathrm{P}$ & $\mathrm{Mn}$ & $\mathrm{Si}$ & $\mathrm{C}$ & $\mathrm{Fe}$ \\
\hline $\mathrm{Wt} \%$ & 0.03 & 0.0054 & 0.029 & 0.007 & 0.009 & 0.4 & 0.01 & 0.08 & 99.3 \\
\hline
\end{tabular}


Table 2. Chemical composition of Ni-P electroless bath.

\begin{tabular}{cc}
\hline Composition of electroless bath & Ni-P \\
\hline Ni sulfide (gr/lit) & 30 \\
Na hypophosphite (gr/lit) & 20 \\
Lactic acid (gr/lit) & 28 \\
propionic acid (gr/lit) & 2.2 \\
$\mathrm{~Pb}(\mathrm{ppm})$ & 1 \\
\hline
\end{tabular}

also to obtain a uniform and well distributed particles. The process is dependent on the type of the particles, their density and weight as well. $\mathrm{Cu}$ particles were added with the increasing amounts of 1, 3, 5 and $7 \mathrm{gr} / \mathrm{lit}$. Three $\mathrm{pH}$ values of 4.5, 7 and 9 were used as well. The composition of the electroless bath for the Ni-P-Cu coating is given in table 3 . $\mathrm{pH}$ measurement was made with the precision of 0.01 by Zag Chemie Co.

Table 3. Composition of the electroless bath for electroplating of Ni-P-Cu composite coating.

\begin{tabular}{cc}
\hline Composition of electroless bath & Ni-P \\
\hline Ni sulfide (gr/lit) & 30 \\
Na hypophosphite (gr/lit) & 20 \\
Lactic acid (gr/lit) & 28 \\
propionic acid (gr/lit) & 2.2 \\
$\mathrm{~Pb}(\mathrm{ppm})$ & 1 \\
$\mathrm{SDS}(\mathrm{gr} / \mathrm{lit})$ & 0.5 \\
$\mathrm{Cu}$ (gr/lit) & $1,3,5,7$ \\
\hline
\end{tabular}

A tube furnance under argon gas was used for the heat treatment of the coatings. The heating rate of the samples was $10^{\circ} \mathrm{C} / \mathrm{min}$. Samples were then cooled in the furnace after heat treatment process.

\subsection{Coating analayses}

XRD tests were performed with Aw-xdm300 model with the line scan of $0.0015^{\circ}$ per second, 0.02 step size to analyze the structure of the coating and to differentiate the phases present. Metallographic examinations were also performed on the coated samples by scanning electron microscope. For this purpose, samples were grinded and polished with the common sample preparation practice. This experiment was performed to make sure of the coating thickness and also to understand the optimum coating time required.

Scanning Electon Microscope, model Phlips XL 30, equipped with EDS analyzer was used to study the morphology of the coatings as well. EDS analysis was used to measure the weight percent of $\mathrm{Ni}, \mathrm{P}$ and $\mathrm{Cu}$ in the composite coatings.

Vickers harndess was performed with Vickers hardness measurement of Bowers model CV400 DAT. Diamond indentor with the angle of $120^{\circ}$ was used in the hardness instrument. $100 \mathrm{gr}$ load was applied for 10 second for each hardness measurement. The hardness data reported are average of five measurement points.

\section{Results and Discussion}

\subsection{Elemental content in the coatings}

\subsubsection{The effect of $\mathrm{Cu}$ particle concentration}

Based on the amount of $\mathrm{P}, \mathrm{Ni}-\mathrm{P}$ electroless can be categorized in three types: low P (1 to $4 \% \mathrm{P})$, medium $\mathrm{P}$ (4 to $7 \% \mathrm{P})$, and high $\mathrm{P}($ above $7 \% \mathrm{P})$. Table 4 gives the amount of Ni and P in Ni-P coatings in weight percent and also in atomic percent as well. Since the amount of $\mathrm{P}$ is reported to be $9.35 \%$, therefore, the applied coating is of a high $\mathrm{P}$ one. Subsequently, the effect of $\mathrm{Cu}$ particles on the weight percent of the major elements (Ni and $\mathrm{P}$ ) was explored. For this purpose, particles were added to the Ni-P electroless bath in $1,3,5$, and $7 \mathrm{gr} /$ lit. The size of $\mathrm{Cu}$ particles in the bath and in the coatings was about 5 microns. In these composites, the concentration of the bath, and the conditions of the bath such as temperature, $\mathrm{pH}$ and the rotation of the bath were considered constant. Temperature was kept at $85^{\circ} \mathrm{C}, \mathrm{pH}=4.5$ and $\mathrm{rpm}=400$. EDS results for all elements with the $\mathrm{Cu}$ amount of 1, 3, 5, and $7 \mathrm{gr} / \mathrm{lit}$ are given in tables 5-8. Figure 1 shows the location where the EDS chemical analysis on the matrix of Ni-P coating was conducted. It is important to emphasis that the chemical analysis was performed on the matrix of composite coatings (curved section).

Table 4. Weight percent and atomic percent of $\mathrm{Ni}$ and $\mathrm{P}$ present in the Ni-P electroless coating.

\begin{tabular}{ccc}
\hline Element & Atomic percent & $\mathrm{Wt} \%$ \\
\hline $\mathrm{Ni}$ & 83.51 & 90.50 \\
$\mathrm{P}$ & 16.35 & 9.35 \\
$\mathrm{Fe}$ & 0.14 & 0.15 \\
\hline
\end{tabular}

Table 5. The amount of different alloying elements in Ni-P- $1 \mathrm{gr} /$ lit $\mathrm{Cu}$ composite coating.

\begin{tabular}{ccc}
\hline Element & Atomic percent & $\mathrm{Wt} \%$ \\
\hline $\mathrm{Ni}$ & 76.82 & 81.67 \\
$\mathrm{P}$ & 13.84 & 7.60 \\
$\mathrm{Cu}$ & 7.84 & 9.17 \\
$\mathrm{Fe}$ & 1.50 & 1.56 \\
\hline
\end{tabular}

Table 6. The amount of different alloying elements in Ni-P- 3gr/ lit $\mathrm{Cu}$ composite coating.

\begin{tabular}{ccc}
\hline Element & Atomic percent & $\mathrm{Wt} \%$ \\
\hline $\mathrm{Ni}$ & 76.93 & 81.03 \\
$\mathrm{P}$ & 12.22 & 6.79 \\
$\mathrm{Cu}$ & 9.39 & 10.71 \\
$\mathrm{Fe}$ & 1.46 & 1.47 \\
\hline
\end{tabular}

Generally, table 9 gives the effect of changes in the concentration of the $\mathrm{Cu}$ particle on the weight percent of Ni-P and on the coating particles. It can be seen from this table that with increasing the concentration of the $\mathrm{Cu}$ particles 
Table 7. The amount of different alloying element in Ni-P- $5 \mathrm{gr} / \mathrm{lit}$ $\mathrm{Cu}$ composite coating.

\begin{tabular}{ccc}
\hline Element & Atomic percent & $\mathrm{Wt} \%$ \\
\hline $\mathrm{Ni}$ & 75.28 & 80.10 \\
$\mathrm{P}$ & 11.56 & 6.01 \\
$\mathrm{Cu}$ & 11.44 & 12.19 \\
$\mathrm{Fe}$ & 1.72 & 1.70 \\
\hline
\end{tabular}

Table 8. The amount of different alloying element in Ni-P- 7gr/lit $\mathrm{Cu}$ composite coating.

\begin{tabular}{ccc}
\hline Element & Atomic percent & $\mathrm{Wt} \%$ \\
\hline $\mathrm{Ni}$ & 75.34 & 79.19 \\
$\mathrm{P}$ & 10.01 & 5.10 \\
$\mathrm{Cu}$ & 12.82 & 13.89 \\
$\mathrm{Fe}$ & 1.83 & 1.82 \\
\hline
\end{tabular}

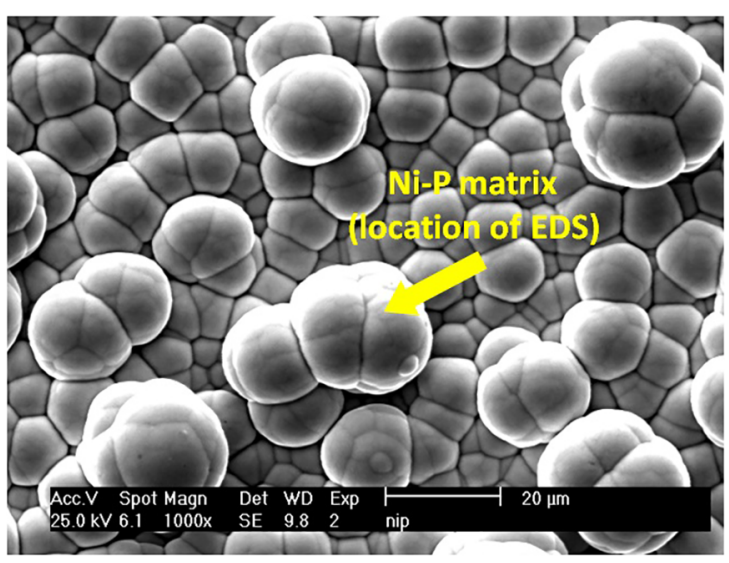

Figure 1. SEM micrograph of Ni-P coating. The location of EDS testing is defined by arrow. Note that there is no $\mathrm{Cu}$ in this coating.

in the electroless bath, the amount of these particles in the composite coatings increases from 9.17 to $13.89 \mathrm{wt} \%$. It is important to mention that by increasing the amount of the $\mathrm{Cu}$ particle, the amount of $\mathrm{Ni}$ and $\mathrm{P}$ in the composite coatings reduce as well.

Table 9. Comparison of the effect of $\mathrm{Cu}$ particles concentration on the amount of $\mathrm{Ni}$ and $\mathrm{P}$ in the coating.

\begin{tabular}{cccc}
\hline $\mathrm{Wt} \%$ of $\mathrm{P}$ & $\mathrm{Wt} \%$ of $\mathrm{Ni}$ & $\begin{array}{c}\mathrm{Wt} \% \text { of } \mathrm{Cu} \\
\text { particle }\end{array}$ & $\begin{array}{c}\text { Concentration } \\
\text { of Cu particle } \\
\text { in the bath } \\
\text { (gr/lit) }\end{array}$ \\
\hline 9.35 & 90.50 & - & 0 \\
7.60 & 81.67 & 9.17 & 1 \\
6.79 & 81.03 & 10.71 & 3 \\
6.01 & 80.10 & 12.19 & 5 \\
5.10 & 79.19 & 13.89 & 7 \\
\hline
\end{tabular}

The microstructure of the Ni-P electroless coatings and also the coating characteristics depend on the amount of $\mathrm{P}$ in the coatings. As mentioned above, coatings with low amount of $\mathrm{P}$ (from 1 to $4 \mathrm{wt} \%$ ) have crystallographic microstructure. The ones with medium amount of $\mathrm{P}$ (from 4 to $7 \mathrm{wt} \%$ ) have a mixture of crystallographic-amorphous microstructure. And coatings with the high amount of $\mathrm{P}$ (above $7 \mathrm{wt} \%$ ) have amorphous microstructure. Therefore, based on table 9, it can be said that Ni-P coating with 9.3 $\mathrm{wt} \% \mathrm{P}$ has a completely amorphous structure, and applied coatings have a mixed crystallographic-amorphous structure. The reason for $\mathrm{Ni}$ and $\mathrm{P}$ weight percent reduction with increasing the concertation of $\mathrm{Cu}$ particles is due to the electroless precipitation of Ni-P composite coatings. In that respect, the $\mathrm{Cu}$ particles were absorbed to the desired subsurface (here low carbon steel). And, this sub-surface is a critical factor in defining the characteristics of the coatings. Electroless precipitation is a self-catalytic process. It means there are active catalytic surfaces for the reduction of $\mathrm{Ni}$ and $\mathrm{P}$ in which with the absorption of secondary particles $(\mathrm{Cu})$ on these active catalytic locations, the amount of $\mathrm{Ni}$ and $\mathrm{P}$ of these locations are reduced as well. Consequently, it reduces the amount of $\mathrm{Ni}$ and $\mathrm{P}$ in the coating. ${ }^{28}$

EDS analyses of Ni-P coating and Ni-P-Cu composite coating are shown in figures 2 and 3 . Iron peak can also be seen in both figures. This is certainly the iron underneath the Fe layer. This is seen in the analysis due to the fact that part of the steel was not properly coated by Ni-P. Therefore, in analyzing those parts, iron is also seen along with other alloying elements of the coating.

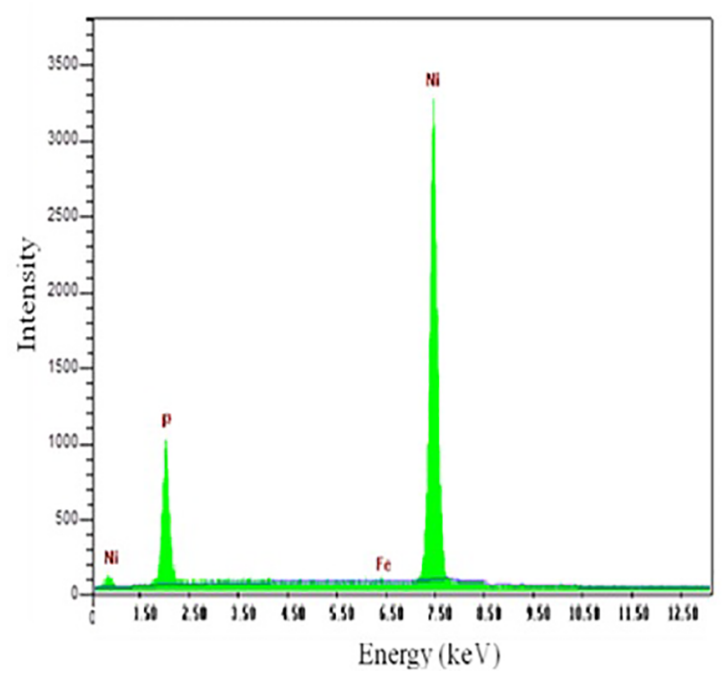

Figure 2. EDS analysis of Ni-P coating.

The location of EDS point analysis of the $\mathrm{Cu}$ particle in the Ni-P coating with $3 \mathrm{gr} / \mathrm{lit}$ of the particle is shown in figure 4 , as well. The percentage of each coating element in this particle is given in table 10 .

It can be seen in table 10 that the percentage of elements are substantially increased when the EDS analysis is directly performed on the particle. Moreover, $\mathrm{Ni}$ and $\mathrm{P}$ were also seen on this particle due mainly to the entrapment of the particle in the metallic matrix of Ni-P. Although, it can be seen that 

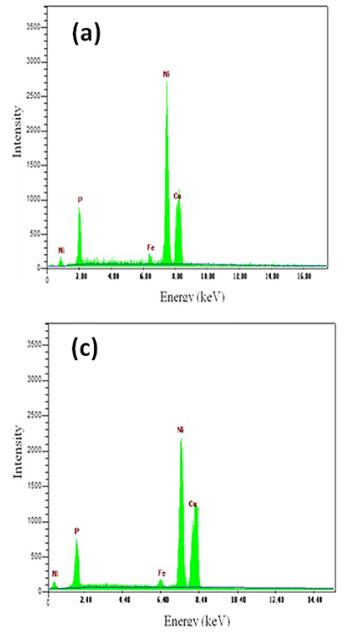

Figure 3. EDS analysis of Ni-P-Cu composite coatings, a) $1 \mathrm{gr} / \mathrm{lit}$ $\mathrm{Cu}$, b) $3 \mathrm{gr} / \mathrm{lit} \mathrm{Cu}$, c) $5 \mathrm{gr} / \mathrm{lit} \mathrm{Cu}$, d) $7 \mathrm{gr} / \mathrm{lit} \mathrm{Cu}$.

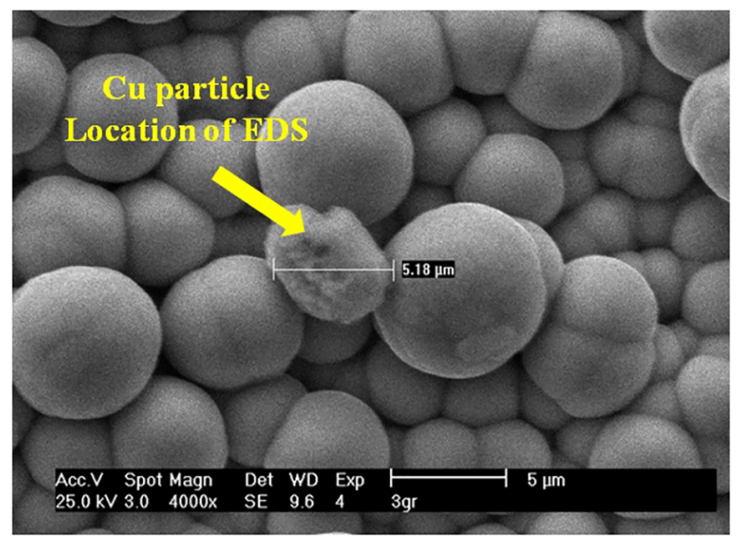

Figure 4. SEM micrograph of the Ni-P-3 gr/lit coating. The location of the EDS analysis is pointed out by arrow.

Table 10. The amount of different elements in the Ni-P-3 gr/lit coating.

\begin{tabular}{ccc}
\hline Element & Atomic percent & $\mathrm{Wt} \%$ \\
\hline $\mathrm{Ni}$ & 6.24 & 5.90 \\
$\mathrm{P}$ & 2.95 & 1.47 \\
$\mathrm{Cu}$ & 88.25 & 90.33 \\
$\mathrm{Fe}$ & 2.56 & 2.30 \\
\hline
\end{tabular}

the amount of $\mathrm{Ni}$ on the particle is much lower than when the EDS analysis is performed on the matrix of Ni-P-3 gr/ lit coating (figure 5).

\subsubsection{The effect of $\mathrm{pH}$ on the amount of alloying elements in the composite coating}

Generally, Ni formation reaction is faster than the $\mathrm{P}$ formation reaction. When the $\mathrm{pH}$ of the solution reduces, $\mathrm{P}$ formation reaction speeds up and the $\mathrm{Ni}$ formation reaction slows down. Therefore, $\mathrm{pH}$ reduction leads to lower precipitation of Ni-P and an increment of $\mathrm{P}$ in the coating as such. The effect of $\mathrm{pH}$ on the precipitation kinetics and the percentage of $\mathrm{P}$ in the coating is given in table 11 .

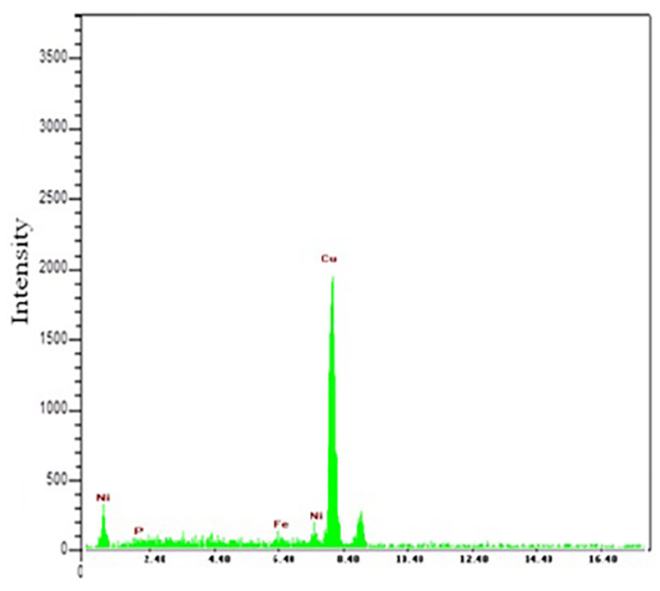

Energy (keV)

Figure 5. EDS analysis of the Ni-P-3 gr/lit composite coating.

Table 11. The effect of $\mathrm{pH}$ on the weight percent of $\mathrm{Ni}, \mathrm{P}$ and $\mathrm{Cu}$ particle in Ni-P-1(gr/lit) Cu coating.

\begin{tabular}{cccc}
\hline $\mathrm{Cu}$ particles $(\mathrm{wt} \%)$ & $\mathrm{P}(\mathrm{wt} \%)$ & $\mathrm{Ni}(\mathrm{wt} \%)$ & $\mathrm{pH}$ \\
\hline 9.17 & 7.60 & 81.67 & 4.5 \\
5.69 & 5.16 & 86.97 & 7 \\
4.11 & 4.12 & 81.27 & 9 \\
\hline
\end{tabular}

\subsection{Coating morphologies}

\subsubsection{Ni-P electroless coating}

The morphology of Ni-P coating is spherical grain which is clearly seen in the SEM micrograph of figure 6 . This figure shows the morphology of Ni-P coating in different magnifications. The spheres, which are Ni-P nucleus, are arranged side by side, and this arrangement produces a Ni-P with a cauliflower characteristic morphology. This morphology is the specification of Ni-P electroless coating. The main reason for the formation of such a morphology is the tendency of Ni-P precipitates for spheroidization to reduce surface energy. The spheres in these coatings have different sizes and their average sizes change with the change of electroless bath condition or with the increment or decrement of coating thickness. It was seen that the size of these spheres increase with the increase of coating thickness. The coating is very dense and uniform. This could be due to the cleanliness of the sub-surface and also due to not adding $\mathrm{Cu}$ particles to the coating.

\subsubsection{The effect of $\mathrm{Cu}$ particles' concentration on morphology of Ni-P-Cu coating}

The concentration of Cuparticles distributed in the electroless bath plays a significant role on the chemical and morphological characteristics of the coating. During the electroless of Ni-P-Cu composite coatings $\mathrm{Cu}$ particles are absorbed to the sub-surface. These particles act as nucleation 


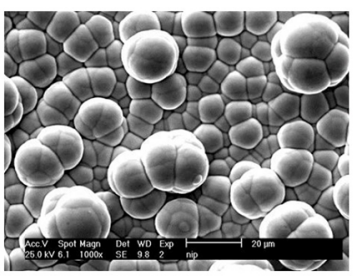

a)

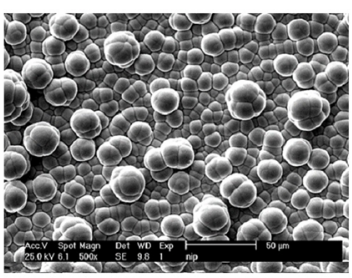

Figure 6. SEM micrographs of Ni-P electroless coating morphology applied on a low carbon steel, a) $1000 \mathrm{mag}$, b) $500 \mathrm{mag}$.

sites and the precipitation of Ni-P alloy covers the surface of the particles. SEM micrographs of Ni-P-Cu coatings with different concentration of $\mathrm{Cu}$ particles are shown in figure 7.

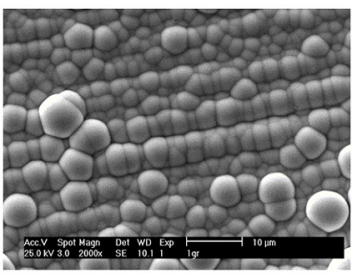

a)

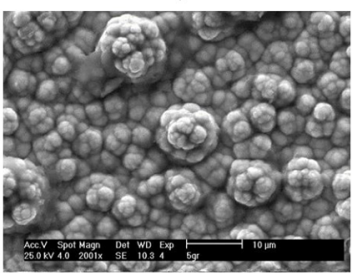

c)

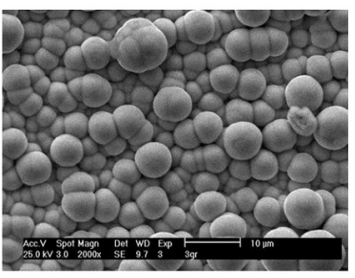

b)

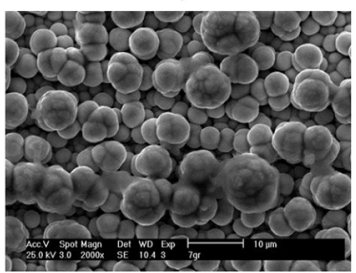

d)
Figure 7. SEM micrographs of Ni-P-Cu coatings and composite coatings of Ni-P-Cu with different concentration of $\mathrm{Cu}$ particles, a) 1 (gr/lit) Cu, b) 3 (gr/lit) Cu, c) 5 (gr/lit) Cu, d) 7 (gr/lit) Cu.

As can be seen in figure 7 , with increasing the concentration of Cuparticles from 1 to $7 \mathrm{gr} / \mathrm{lit}$, the particles get agglomerated and form laths structure. These particles can affect the uniformity of the coating. It can also be seen in this figure that the distance between the spheres increases with increasing the concentration of the $\mathrm{Cu}$ particles in the bath. The uniformity of the coating is reduced in such a situation. Another reason is the fact that these particles act as nucleation sites for the precipitation of Ni-P in the bath. For these reasons the density of Ni-P matrix is reduced as the amount of these particles increase in the coating.

\subsubsection{The effect of $\mathrm{pH}$ on the morphology of $\mathrm{Ni}-\mathrm{P}-\mathrm{Cu}$ composite coating}

Figure 8 shows SEM micrographs of Ni-P-Cu coatings in $\mathrm{pHs}$ of 4.5, 7 and 9.

As explained before Ni-P electroless coating has a spherical shape grains morphology which are arranged side by side forming a cauliflower characteristic. The size of these spheres depends on the precipitation rate of Ni-P electroless
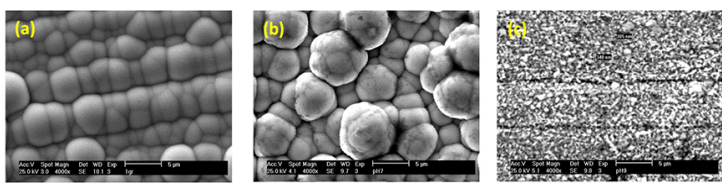

Figure 8. SEM micrographs of Ni-P coating and Ni-P-Cu composite coating with different $\mathrm{pHs}$ of the solution: a) $\mathrm{pH}=4.5$, b) $\mathrm{pH}=7$, c) $\mathrm{pH}=9$.

coating on the sub-surface and also on the nucleation sites on the sub-surface. With increasing the $\mathrm{pH}$ of the solution, which leads to an increase of the coating rate, the growth rate of these spheres increases. This is due to the dominance of the growth mechanism over the nucleation mechanism at higher pHs. As shown in this figure, the size of the sphere in $\mathrm{pH}$ of 7 is bigger than $\mathrm{pHs}$ of 4.5 and 9. The spheres are small in $\mathrm{pH}$ of 4.5 due to lower growth rate mechanism and the more active role of nucleation compared to high $\mathrm{pHs}$. However, this situation is reversed in $\mathrm{pH}$ of 9 because of the alkaline nature of the bath.

\subsection{The effect of heat treatment on the microstructure of $\mathrm{Ni}-\mathrm{P}-3$ (gr/lit) $\mathrm{Cu}$ electroless coating}

An XRD analysis of the coating prior to heat treatment is shown in figure 9. As can be seen in this figure, the structure is a mixed of crystalline and amorphous. Medium amount of $\mathrm{pH}$ in the Ni-P-3 (gr/lit) $\mathrm{Cu}$ coating is the main reason for the formation of this morphology. As explained before medium range $P$ content coatings have a mixed of crystalline and amorphous structure. The microstructure of the coating changes to a fully crystalline one from amorphous after conducting heat treatment at $400^{\circ} \mathrm{C}$ for one hour. This is shown in figure 10. As can be seen in the analysis of heat treated coating, Ni phosphate crystalline precipitates $\left(\mathrm{Ni}_{3} \mathrm{P}\right)$ are formed in the matrix. In coatings with $\mathrm{P}$ level lower than $7 \mathrm{wt} \%$, the matrix is a mixed of $\mathrm{Ni}$ and $\mathrm{Ni}$ phosphate $\left(\mathrm{Ni}_{3} \mathrm{P}\right)$ after heat treatment. Crystallization of the structure after heat treatment makes the coating harder. Generally, materials tend to lower their energy level. This is true for the case of $\mathrm{Ni}$ and $\mathrm{P}$ elements to get more stabilized. Therefore, this is the main reason for the formation of an important intermetallic phase such as $\mathrm{Ni}_{3} \mathrm{P}$. At the temperature of $400^{\circ} \mathrm{C}$, the energy level of both elements is lowered in the $\mathrm{Ni}_{3} \mathrm{P}$ compound. To achieve this stable situation, it is required to overcome an activation energy barrier. Such an activation energy is overcome through heat treatment at a relatively high temperature of $400^{\circ} \mathrm{C}$ for this coating..$^{29}$

\subsection{Hardness of $\mathrm{Ni}-\mathrm{P}-\mathrm{Cu}$ composite coatings}

\subsubsection{Effect of the amount of $\mathrm{Cu}$ particles on the hardness of the composite coating}

Hardness of the coating is an important characteristics of the coatings applied on the surface. The hardness of Ni-P-Cu 


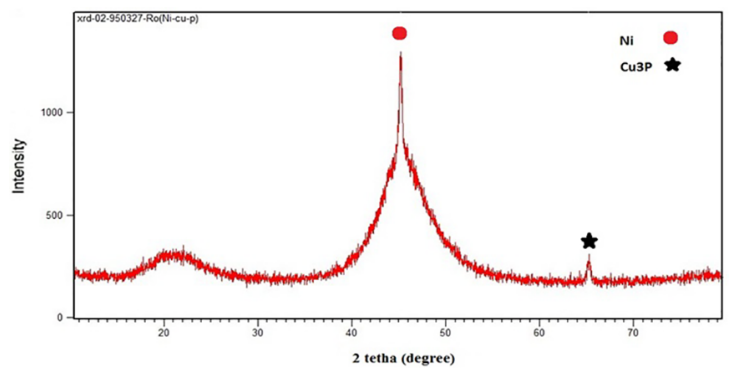

Figure 9. XRD analysis of Ni-P-3(gr/lit) Cu coating prior to heat treatment.

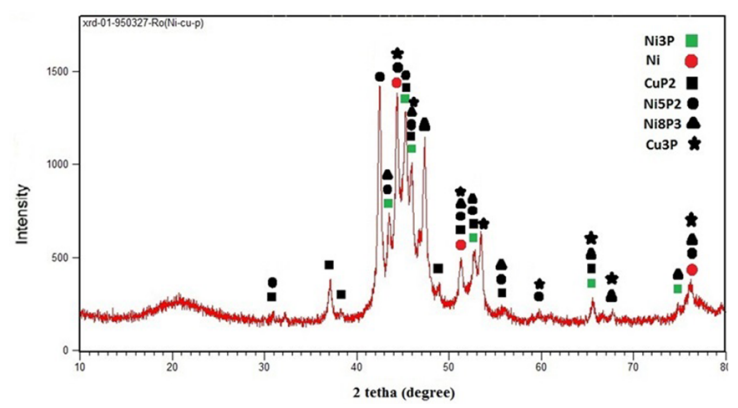

Figure 10. XRD analysis of Ni-P- 3(gr/lit) $\mathrm{Cu}$ coating after heat treatment for one hour at $400^{\circ} \mathrm{C}$

coatings with different amount of $\mathrm{Cu}$ particles are shown in table 12. It can be seen in this table that the hardness of the composite coatings is lower than the hardness of the simple coating of Ni-P. The hardness of Ni-P coating is $482.4 \mathrm{VH}$ while the hardness of the Ni-P-Cu composite coating with $7 \mathrm{gr} /$ lit $\mathrm{Cu}$ particle is $380.7 \mathrm{VH}$. The main reason for the lower hardness of the composite coating compared to the simple Ni-P coating is the softening nature of $\mathrm{Cu}$. Therefore, the hardness of the coating increased as the amount of $\mathrm{Cu}$ particles increased. As can be seen in table 9, the weight percent of $\mathrm{P}$ is reduced with the increase of the concentration of $\mathrm{Cu}$ particles. And lower $\mathrm{P}$ content is tantamount with high hardness of the coating.

Table 12. The effect of $\mathrm{Cu}$ particles on the hardness of Ni-P-Cu composite coating.

\begin{tabular}{cc}
\hline $\begin{array}{c}\text { Concentration of } \mathrm{Cu} \text { particle in } \\
\text { the bath }(\mathrm{gr} / \mathrm{lit})\end{array}$ & Vickers Hardness $(\mathrm{HV})$ \\
\hline- & 482.4 \\
1 & 351.2 \\
3 & 359.9 \\
5 & 365.5 \\
7 & 380.7 \\
\hline
\end{tabular}

\subsubsection{The effect of $\mathrm{pH}$ on the hardness of composite coating}

It was found that the percentage of $\mathrm{P}$ in the coating reduces as the $\mathrm{pH}$ increases. This is the case for acidic and neutral environments. The hardness of the composite coating increases with increasing the $\mathrm{pH}$, as can be seen in table 13. This is due to the changes in the microstructure of the coating from amorphous to crystalline as the amount of $P$ reduces. And the crystalline structure has a higher hardness compared with the amorphous one. ${ }^{30}$ However, the hardness of the coating has reduced at the $\mathrm{pH}$ of 9 due mainly to the alkaline nature of the environment. The hardness increases with the increase of $\mathrm{P}$ for the $\mathrm{pH}$ in the alkaline range.

Table 13. The effect of $\mathrm{pH}$ on the hardness of composite coatings.

\begin{tabular}{cc}
\hline $\mathrm{pH}$ of electroless bath & Vickers Hardness (HV) \\
\hline 4.5 & 351.2 \\
7 & 373.5 \\
9 & 176.4 \\
\hline
\end{tabular}

\section{Conclusions}

The effect of $\mathrm{pH}$, and the amount of $\mathrm{Cu}$ on the morphology, hardness, and the amount of alloying elements in Ni-P and $\mathrm{Ni}-\mathrm{P}-\mathrm{Cu}$ compositing coatings were investigated in this research. As well, the effect of heat treatment on the coating properties was analyzed. The following results were obtained:

1. In the coating with $1 \mathrm{gr} / \mathrm{lit} \mathrm{Cu}$ particle, the amount of $\mathrm{P}$ of the coating reduced from 7.06 to 4.12 by increasing the $\mathrm{pH}$ from 4.5 to 9 . Therefore, increasing $\mathrm{pH}$ has reduced $\mathrm{P}$ due mainly to the fact that at higher $\mathrm{pH}$, the reduction and precipitation of $\mathrm{Ni}$ is faster than $\mathrm{P}$.

2. Cauliflowers morphology of the Ni-P coating was detected by SEM micrographs. And agglomeration was happening as the concentration of the particles increases from 1 to $7 \mathrm{gr} /$ lit. The formation of lath features would affect the uniformity of the coating.

3. The growth rate of spheres was higher at higher $\mathrm{pHs}$ due to higher rate of coating. The dominance of growth over nucleation at higher pHs was explained to be the reason for this behavior. More spheres were formed by increasing the $\mathrm{pH}$ from 4.5 to 7 . While this trend was reversed by increasing the $\mathrm{pH}$ from 7 to 9 .

4. Heat treatment for one hour at $400^{\circ} \mathrm{C}$ increased the hardness of the coatings substantially. This was due to the precipitation hardening effect of $\mathrm{Ni}_{3} \mathrm{P}$ intermetallic phase. Moreover, the structure of mixed amorphous and crystalline nature changes to a fully crystalline one with the matrix of $\mathrm{Ni}$ and $\mathrm{Ni}_{3} \mathrm{P}$ after performing the heat treatment process.

5. Although adding $\mathrm{Cu}$ particles reduced the hardness of Ni-P coating, within Ni-P-Cu composite coatings the hardness of Ni-P-Cu composite coating increased from 351.2 to 380.7 by increasing the $\mathrm{Cu}$ particles from 1 to $7 \mathrm{gr} /$ lit. In fact, the higher the amount of particles in the coating, the higher would be the hardness values. The amount $P$ was explained as the main reason for this increment. 
6. Hardness of the composite coating increased with increasing the $\mathrm{pH}$ due to the fact that reducing $\mathrm{P}$ of the coating changes its structure from amorphous to crystalline. Though, the hardness at the $\mathrm{pH}$ of 9 was reduced as the result of alkaline nature of the bath.

\section{References}

1. Bonin L, Bains N, Vitry V, Cobley AJ. Electroless deposition of nickel-boron coatings using low frequency ultrasonic agitation: Effect of ultrasonic frequency on the coatings. Ultrasonics. 2017;77:61-68.

2. Amdouni S, Rahmani M, Zaïbi MA, Oueslati M. Enhancement of porous silicon photoluminescence by electroless deposition of nickel. Journal of Luminescence. 2015:157:93-97.

3. Lavvafi H, Lewandowski ME, Schwam D, Lewandowski JJ. Effects of surface laser treatments on microstructure, tension, and fatigue behavior of AISI 316LVM biomedical wires. Materials Science and Engineering: A. 2017;688:101-113.

4. Sadeghzadeh-Attar A, AyubiKia G, Ehteshamzadeh M. Improvement in tribological behavior of novel sol-enhanced electroless Ni-P-SiO 2 nanocomposite coatings. Surface and Coatings Technology. 2016;307(Pt A):837-848.

5. Beigi Khosroshahi N, Azari Khosroshahi R, Taherzadeh Mousavian R, Brabazon D. Effect of electroless coating parameters and ceramic particle size on fabrication of a uniform Ni-P coating on SiC particles. Ceramics International. 2014;40(8 Pt A):1214912159.

6. Gan Y, Chen D, Kang Z. A highly anticorrosive chromiumfree conversion coating prepared on electroless Ni-P coating. Surface and Coatings Technology. 2016;287:25-32.

7. Wang C, Farhat Z, Jarjoura J, Hassan MK, Abdullah AM. Indentation and erosion behavior of electroless Ni-P coating on pipeline steel. Wear. 2017;376-377(Pt B):1630-1639.

8. Zuleta AA, Correa E, Castaño JG, Echeverría F, Baron-Wiechec A, Skeldon P, et al. Study of the formation of alkaline electroless Ni-P coating on magnesium and AZ31B magnesium alloy. Surface and Coatings Technology. 2017;321:309-320.

9. Liu Y, Beckett D, Hawthorne D. Effect of heat treatment, top coatings and conversion coatings on the corrosion properties of black electroless Ni-P films. Applied Surface Science. 2011;257(9):4486-4494.

10. Shu X, Wang Y, Lu X, Liu C, Gao W. Parameter optimization for electroless Ni-W-P coating. Surface and Coatings Technology. 2015;276:195-201.

11. Ivanov MV. Electroless Nickel-Boron-Phosphorus Coatings: Protective and Functional Properties. Protection of Metals. 2001;37(6):592-596.

12. Boubatra M, Azizi A, Schmerber G, Dinia A. The influence of $\mathrm{pH}$ electrolyte on the electrochemical deposition and properties of nickel thin films. Ionics. 2012;18(4):425-432.

13. Ansari MI, Thakur DG. Effect of pH Bath on Phosphorus Content in Electroless Nickel-Phosphorus Deposit. International Journal For Technological Research In Engineering. 2015;2(7):11201124.
14. Julka S, Ansari MI, Thakur DG. Effect of $\mathrm{pH}$ on mechanical, physical and tribological properties of electroless Ni-P- $\mathrm{Al}_{2} \mathrm{O}_{3}$ composite deposits for marine applications. Journal of Marine Science and Application. 2016;15(4):484-492.

15. Ajibola OO, Oloruntoba DT, Adewuy BO. Effect of Processing Parameters on the Protective Quality of Electroless NickelPhosphorus on Cast Aluminium Alloy. Journal of Metallurgy. 2015;2015:386347.

16. Bonin L, Vitry V. Mechanical and wear characterization of electroless nickel mono and bilayers and high boron-mid phosphorus electroless nickel duplex coatings. Surface and Coatings Technology. 2016;307(Pt A):957-962.

17. Farzaneh A, Mohammadi M, Ehteshamzadeh M, Mohammadi F. Electrochemical and structural properties of electroless Ni-P-SiC nanocomposite coatings. Applied Surface Science. 2013;276:697-704.

18. Baibordi A, Amini K, Bina MH, Dehghan A. The effect of heat treatment temperature on the properties of the composite duplex electroless coating of Ni-P/Ni-B-BN containing boron nitride nanoparticles. Kovové Materiály. 2014;52(5):263-268.

19. Antihovich IV, Ablazhey NM, Chernik AA, Zharsky IM. Electrodeposition of Nickel and Composite Nickel-fullerenol Coatings from Low-temperature Sulphate-chloride-isobutyrate Electrolyte. Procedia Chemistry. 2014;10:373-377.

20. Zarebidaki A, Allahkaram SR. Effect of heat treatment on the properties of electroless Ni-P-carbon nanotube composite coatings. IET Micro \& Nano Letters. 2012;7(1):90-94.

21. Yildiz RA, Genel K, Gulmez T. Effect of Heat Treatments for Electroless Deposited Ni-B and Ni-W-B Coatings on 7075 $\mathrm{Al}$ Alloy. International Journal of Materials, Mechanics and Manufacturing. 2017;5(2):83-86.

22. Kundu S, Das SK, Sahoo P. Properties of Electroless Nickel at Elevated Temperature-a Review. Procedia Engineering. 2014;97:1698-1706.

23. Wu W, Eliaz N, Gileadi E. The Effects of $\mathrm{pH}$ and Temperature on Electrodeposition of Re-Ir-Ni Coatings from Aqueous Solutions. Journal of The Electrochemical Society. 2015;162(1):D20-D26.

24. Ambat R, Zhou W. Electroless nickel-plating on AZ91D magnesium alloy: effect of substrate microstructure and plating parameters. Surface and Coatings Technology. 2004;179(23):124-134.

25. Guo C, Zuo Y, Zhao X, Zhao J, Xiong J. The effects of pulsereverse parameters on the properties of $\mathrm{Ni}$-carbon nanotubes composite coatings. Surface and Coatings Technology. 2007;201(24):9491-9496.

26. Anik M, Körpe E, Sen E. Effect of coating bath composition on the properties of electroless nickel-boron films. Surface and Coatings Technology. 2008;202(9):1718-1727.

27. Aal AA, Aly MS. Electroless Ni-Cu-P plating onto open cell stainless steel foam. Applied Surface Science. 2009;255(1314):6652-6655.

28. Balaraju JN, Narayanan TSNS, Seshadri SK. Structure and phase transformation behavior of electroless Ni-P composite coatings. Materials Research Bulletin. 2006;41(4):847-860. 
29. Kobets AV, Vorobyova TN. Palladium catalyst synthesis through sol-gel processing for electroless nickel deposition on glass. Thin Solid Films. 2016;616:793-799.
30. Tachev D, Georgieva J, Armyanov S. Magnetothermal study of nanocrystalline particle formation in amorphous electroless Ni-P and Ni-Me-P alloys. Electrochimica Acta. 2001;47(12):359-369 